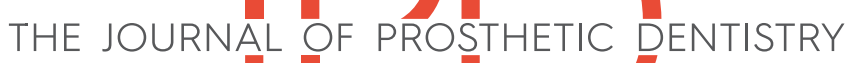

RESEARCH AND EDUCATION

\section{Comparison of conventional and plant-extract disinfectant solutions on the hardness and color stability of a maxillofacial elastomer after artificial aging}

\author{
Aimée Maria Guiotti, DDS, MSc, PhD, ${ }^{a}$ Marcelo Coelho Goiato, DDS, MSc, PhD, ${ }^{b}$ \\ Daniela Micheline dos Santos, DDS, MSc, PhD, ${ }^{c}$ Aljomar José Vechiato-Filho, DDS, MSc, ${ }^{d}$ \\ Bruno Guandalini Cunha, DDS, ${ }^{e}$ Marcela Borghi Paulini, DDS, ${ }^{f}$ Amália Moreno, DDS, MSc, PhD, ${ }^{g}$ and \\ Margarete Teresa Gottardo de Almeida, MSc, PhD
}

Maxillofacial prostheses should restore the esthetics of patients with facial deformities and improve their quality of life. ${ }^{1}$ However, one of the most distressing and limiting aspects of this rehabilitation is that after a few months of clinical performance, these prostheses are unsatisfactory because of alterations in the silicone elastomer color and hardness, the distortion of the prosthesis margins, and a reduction in their tear resistance. ${ }^{2,3}$ The degradation of maxillofacial silicone elastomers is caused by ultraviolet rays and by handling, cleaning, and removal when the prosthesis is glued to the skin with medical adhesive. ${ }^{4-12}$

Pigmentation is important in fabricating a successful

\begin{abstract}
Statement of problem. Silicone elastomers undergo physical and chemical degradation with disinfecting solutions. Phytotherapy may be a suitable solution for disinfection. However, its effect on the properties of the silicone material is unknown.
\end{abstract}

Purpose. The purpose of this in vitro study was to evaluate the effect of disinfection with conventional and plant-extract solutions and of artificial aging on the hardness and color stability of a facial silicone associated with pigments and an opacifier.

Material and methods. Four hundred specimens of silicone (MDX4-4210) were fabricated (5×6 $\mathrm{mm})$. Two pigment shades and 1 dry opacifier were combined in the tested material, and 4 groups $(n=10)$ were obtained: colorless $(G I)$, colorless with opacifier (GII), medium pigment with opacifier (GIII), and black pigment with opacifier (GIV). Specimens were subjected to disinfection (30 days) using saline solution, water, and neutral soap (digital friction, 30 seconds), chlorhexidine 4\%, Hydrastis canadensis, and Cymbopogon nardus extracts (immersion, 10 minutes). Shore A hardness (ASTM D2240) and color analyses were performed before and after disinfection. Specimens were then exposed to 1008 hours of artificial aging (ASTM 53) and subjected to final hardness and color readings. The results were analyzed with ANOVA and the Tukey significant difference test $(\alpha=.05)$.

Results. The opacifier increased the hardness (GII). For Gll, the $H$. canadensis solution and the friction with water and soap promoted significantly reduced hardness; the friction also promoted a reduction in this property for GIV. The GIII was not affected after disinfection. A significant difference was found between the $\Delta \mathrm{E}$ values of the specimens disinfected with $H$. canadensis, $C$. nardus, and chlorhexidine, and specimens subjected to saline solution and neutral soap.

Conclusion. The hardness of MDX4-4210 after the experimental procedure was considered clinically acceptable for facial prostheses. All groups showed clinically unacceptable color alterations regardless of the disinfecting solution. (J Prosthet Dent 2016;115:501-508)

\footnotetext{
Supported by FundUNESP (0048/004/13 - PROPe/CDC).

${ }^{a}$ Assistant Professor, Department of Dental Materials and Prosthodontics, Araçatuba Dental School, São Paulo State University (UNESP), São Paulo, Brazil.

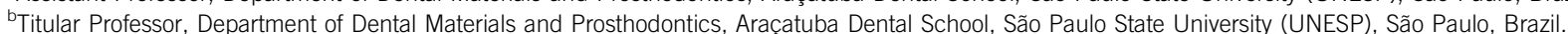

cAssistant Professor, Department of Dental Materials and Prosthodontics, Araçatuba Dental School, São Paulo State University (UNESP), São Paulo, Brazil.

${ }^{d}$ Doctoral student, Department of Dental Materials and Prosthodontics, Araçatuba Dental School, São Paulo State University (UNESP), São Paulo, Brazil.

'Graduate student, Department of Dental Materials and Prosthodontics, Araçatuba Dental School, São Paulo State University (UNESP), São Paulo, Brazil.

fGraduate student, Department of Dental Materials and Prosthodontics, Araçatuba Dental School, São Paulo State University (UNESP), São Paulo, Brazil.

gProfessor, Oral Patology and Surgery Department, School of Dentistry, Federal University of Minas Gerais, Minas Gerais, Brazil.

hProfessor, Department of Dermatologic, Infectious and Parasitic Diseases, Medical School, FAMERP, São Paulo, Brazil.
} 


\section{Clinical Implications}

Phytotherapy solutions may be suitable for disinfecting silicone for facial prostheses, in that the elastomers' Shore A hardness was preserved. However, these solutions also promoted color alteration of the silicone material. Thus, modifications of their composition are needed to prevent prosthetic complications.

maxillofacial prosthesis. Intrinsic and extrinsic colorings are often used to match a prosthesis to human tissue in clinical practice. Intrinsic coloring is less vulnerable to environmental conditions and handling but more likely to affect the structure and properties of the mixture. ${ }^{13-15}$ Some studies have shown that the incorporation of nano-oxides (such as, $\mathrm{ZnO}, \mathrm{TiO}_{2}$, and $\mathrm{CeO}_{2}$ ) as dry opacifiers improved the overall mechanical properties of silicone elastomers and that they may increase the lifetime of prostheses. ${ }^{15-19}$ However, even with this strategy, silicone elastomers are far from ideal. ${ }^{6}$

Some unavoidable situations, such as cleaning, may also promote the degradation of the properties of silicone material. ${ }^{18,20}$ Although the disinfection of maxillofacial prostheses is essential in providing healthy surroundings, some authors have suggested that digital friction, even when gently performed, induces the detachment of the compounds incorporated into the elastomer matrix for the characterization of maxillofacial silicone prostheses. ${ }^{18,21}$ Chemical disinfection through immersion is a proposed alternative for cleaning silicone prostheses. ${ }^{18}$ However, a plethora of disinfecting solutions (neutral soap, sodium hypochlorite $1 \%$, cleansing tablets, commercial antimicrobial solutions, and chlorhexidine $2 \%$ to $4 \%)$, concentrations, and methods of handling are available, but all of them seem to affect the properties of an elastomer material. ${ }^{18,21-24}$ According to some recent studies, the optimal disinfecting solution is still a matter of discussion. ${ }^{21-23}$

Phytotherapy may be a promising alternative for infections mainly because of its low cost and satisfactory antimicrobial properties. ${ }^{25}$ Cymbopogon nardus and Hydrastis canadensis are plants that provide extracts with antimicrobial and antifungal properties. This action is produced by deleterious morphologic changes in cellular structures and on surfaces. ${ }^{26,27}$ They may also be useful for a wide range of microorganisms because such plant compounds kill both yeast and filamentous fungi formations, ${ }^{28}$ suggesting that these solutions might be useful as topical agents for silicone elastomers. However, to the best of the authors' knowledge, no studies have evaluated whether those disinfecting solutions can be used for facial silicone without affecting its properties.
The silicone elastomer Silastic MDX4-4210 is the most commonly used material for maxillofacial prosthesis fabrication. ${ }^{16,17,29,30}$ It has good flexibility, its texture is closest to the ideal, and it is comfortable for the patient. 7,9 To evaluate in vitro the clinical performance of silicone elastomers, some studies have proposed artificial aging, allowing the analysis of environmental conditions that may degrade maxillofacial prostheses and reduce their lifetime. ${ }^{18,24,31}$ Still, the effect of artificial aging on previously disinfected silicone elastomers has not been clearly investigated.

The purpose of this study was to evaluate the effect of disinfection with conventional and phytotherapy solutions and artificial aging on the Shore A hardness and color stability $(\Delta \mathrm{E})$ of a maxillofacial silicone elastomer associated with a dry opacifier or oil pigments. The null hypothesis was that the pigments and opacifier used, the disinfecting solutions, and artificial aging would not affect the hardness or the color stability of the tested silicone elastomer.

\section{MATERIAL AND METHODS}

The materials used in the present study are listed in Table 1. Four hundred disk-shaped specimens ( $5 \mathrm{~mm}$ in diameter, $6 \mathrm{~mm}$ in thickness) of 1 maxillofacial silicone elastomer were fabricated using a metallic matrix. ${ }^{9}$ The specimens were distributed into 4 groups (GI, GII, GIII, GIV), each of which was divided into 5 subgroups. The factors evaluated were pigmentation (pigments/opacifier) at 4 levels, disinfecting solutions at 5 levels, and periods at 3 levels. The factorial design of this study was $4 \times 5 \times 3$ (repeated measure) for the experimental groups, resulting in 20 subgroups $(n=10)$, containing all combinations formed from the different levels of factors. For the specimen's fabrication, the colorless silicone elastomer and the pigments were weighed in a digital precision balance (Mark M214Ai; BEL Engineering). The quantity of the pigment was $0.2 \mathrm{wt} \%$, whereas the opacifier was $2.0 \mathrm{wt} \% .^{9,19}$ The silicone elastomer was manually mixed in a ratio of 10:1 (base:catalyst), according to the manufacturer's instructions. ${ }^{8}$ The pigments and opacifier were mixed in the silicone elastomer matrix with a stainless steel spatula on a glass plate until a homogenous mixture was obtained. After handling, the silicone elastomer was poured into a metallic matrix, and the surface was exposed to the room environment for 3 days until polymerization was complete.

Specimens were submitted to initial hardness evaluation. A digital Shore A durometer (GSD 709, Teclock) was used to test the hardness of the specimens, according to ASTM specification D2240. ${ }^{32}$ The hardness values are expressed in Shore units (range 0 to 100). For all specimens, 3 readings were made, and the average value calculated. ${ }^{7,33,34}$ The hardness was considered 
Table 1. Materials used

\begin{tabular}{|c|c|c|c|}
\hline Material & Manufacturer & Color/number & Batch No. \\
\hline $\begin{array}{l}\text { MDX4-4210 } \\
\text { (poly (dimethylsiloxane)) }\end{array}$ & $\begin{array}{l}\text { Dow Corning } \\
\text { Corporation }\end{array}$ & Colorless & 0007491879 \\
\hline $\begin{array}{l}\text { Functional Intrinsic } \\
\text { II - Silicone Coloring } \\
\text { System }\end{array}$ & Factor II Inc & $\begin{array}{l}\text { Medium shade } \\
\text { (Tan FI - 215) }\end{array}$ & B042811 \\
\hline $\begin{array}{l}\text { Functional Intrinsic } \\
\text { II - Silicone Coloring } \\
\text { System }\end{array}$ & Factor II Inc & $\begin{array}{l}\text { Black shade } \\
\text { (Black FI - 205) }\end{array}$ & SB041411 \\
\hline $\begin{array}{l}\text { Dry opacifier } \\
\text { (Zinc oxide - ZnO) }\end{array}$ & Pharmacotecnica & Colorless & XZY120901Y \\
\hline Saline solution & Tayuyna Laboratory & _ & 252731 \\
\hline Neutral soap & Johnson \& Johnson & _ & 0854B01 \\
\hline Chlorhexidine $4 \%$ & Pharmacotecnica & - & $12082486 \mathrm{~A}$ \\
\hline $\begin{array}{l}\text { Hydrastis canadensis } \\
\text { (Hydrastis) }\end{array}$ & $\begin{array}{l}\text { Schraiber } \\
\text { Homeopatia }\end{array}$ & - & 5475 \\
\hline $\begin{array}{l}\text { Cymbopogon nardus } \\
\text { (Cytronella) }\end{array}$ & $\begin{array}{l}\text { Pharmaspecial } \\
\text { Espec }\end{array}$ & - & PS-002545/F01 \\
\hline
\end{tabular}

clinically acceptable when specimens showed a Shore A result from 25 to 35 . This range has been established for maxillofacial prostheses used for 6 months to 1 year. ${ }^{35}$

The color was analyzed with an ultraviolet-visible reflection spectrophotometer (UV-2450; Shimadzu Corp). ${ }^{18,36-38}$ Color changes were calculated according to $\mathrm{CIELab}^{39}$ with the formula $\Delta \mathrm{E}=\left[(\Delta \mathrm{L})^{2}+(\Delta \mathrm{a})^{2}+(\Delta \mathrm{b})^{2}\right]^{1 / 2}$. The $\Delta \mathrm{E}$ means were classified into 3 clinically relevant intervals ${ }^{40-43}$ as follows: $\Delta \mathrm{E}<1$ (undetectable color alteration); $1<\Delta \mathrm{E}<3.3$ (clinically acceptable color alteration); and $\Delta \mathrm{E}>3.3$ (clinically unacceptable color alteration).

Next, specimens were disinfected daily for 30 days with different disinfecting solutions in the following cleaning cycles: saline solution (SS); digital friction for 30 seconds with water and neutral soap (WN); chlorhexidine 4\% (CHX), immersion for 10 minutes; Hydrastis canadensis extract $(\mathrm{HC})$, immersion for 10 minutes; and Cymbopogon nardus extract $(\mathrm{CN})$, immersion for 10 minutes.

Artificial aging was conducted in an aging chamber for nonmetallic specimens (EQUV; Equilan) according to specification 53 of the American Society for Testing and Materials (ASTM).$^{44}$ Specimens were exposed to 1008 hours of artificial aging and then subjected to final $\mathrm{SH}$ hardness readings. The hardness test and the color analysis were performed on the same specimens but in 3 different periods as follows: at the baseline (B), after 30 days of chemical disinfection (T1), and after 1008 hours of artificial aging (T2). All obtained data were cumulative. A multifactorial design provided a more relevant clinical scenario since facial prostheses are subjected to factors that affect the properties of silicone material simultaneously when exposed to the environment.

The color alterations were calculated after 30 days of chemical disinfection (T1B) and after 1008 hours of artificial aging (T2B) with regard to baseline (B). In addition, to understand the interaction between the silicone
Table 2. Results of 3-way ANOVA for Shore A hardness

\begin{tabular}{|c|c|c|c|c|c|}
\hline Source & $d f$ & $\begin{array}{l}\text { Sum of } \\
\text { Squares }\end{array}$ & $\begin{array}{l}\text { Mean } \\
\text { Square }\end{array}$ & $\mathbf{F}$ & $\boldsymbol{P}$ \\
\hline Pigmentation & 3 & 459487 & 153162 & 27465 & $<.001^{*}$ \\
\hline Disinfectant & 4 & 44847 & 11212 & 2011 & .095 \\
\hline Pigmentation $\times$ disinfectant & 12 & 183695 & 15308 & 2745 & $.002^{*}$ \\
\hline Between specimens & 180 & 1003792 & 5577 & & \\
\hline Period & 2 & 273079 & 136539 & 72208 & $<.001^{*}$ \\
\hline Period $\times$ pigmentation & 6 & 292892 & 48815 & 25816 & $<.001^{*}$ \\
\hline Period $\times$ disinfectant & 8 & 71020 & 8877 & 4695 & $<.001^{*}$ \\
\hline Period $\times$ pigmentation $\times$ disinfectant & 36 & 319449 & 8874 & 4693 & $<.001^{*}$ \\
\hline Within specimens & 360 & 680735 & 1891 & & \\
\hline
\end{tabular}

Table 3. Results of 3-way ANOVA for color stability

\begin{tabular}{|c|c|c|c|c|c|}
\hline Source & $d f$ & $\begin{array}{l}\text { Sum of } \\
\text { Squares }\end{array}$ & $\begin{array}{l}\text { Mean } \\
\text { Square }\end{array}$ & $\mathbf{F}$ & $\boldsymbol{P}$ \\
\hline Pigmentation & 3 & 785066 & 261689 & 47785 & $<.001^{*}$ \\
\hline Disinfectant & 4 & 463281 & 115820 & 21149 & $<.001^{*}$ \\
\hline Pigmentation $\times$ disinfectant & 12 & 264568 & 22047 & 4026 & $<.001 *$ \\
\hline Between specimens & 180 & 985753 & 5476 & & \\
\hline Period & 1 & 417048 & 417048 & 75281 & $<.001^{*}$ \\
\hline Period $\times$ pigmentation & 3 & 533106 & 177702 & 32077 & $<.001^{*}$ \\
\hline Period $\times$ disinfectant & 4 & 109598 & 27400 & 4946 & $<.01^{*}$ \\
\hline Period $\times$ pigmentation $\times$ disinfectant & 24 & 291344 & 12139 & 2191 & $<.01^{*}$ \\
\hline Within specimens & 180 & 997182 & 5540 & & \\
\hline
\end{tabular}

${ }^{*} P<.05$ shows statistically significant difference.

elastomer and the tested pigments, 1 specimen of each pigmented group was analyzed through energy dispersive spectroscopy (EDS - JSM 610LA; JEOL), allowing for the mapping of chemical components on the surface of each specimen using $\mathrm{x}$-rays. ${ }^{45}$

The factors evaluated were pigmentation (pigments/ opacifier) at 4 levels, disinfecting solutions at 5 levels, and periods at 3 levels; they were submitted to 3-way analysis of variance (ANOVA) through a repeated model of factorial analysis. The means were then compared with the Tukey (HSD) test $(\alpha=.05)$, performed with software (SPSS v19.0; IBM Corp). The EDS graphics were visually compared among the pigmented groups.

\section{RESULTS}

The 3-way ANOVA revealed a significant difference in the interactions of all the factors (pigmentation $\times$ disinfectants $\times$ period; $P<.001)$ after the baseline $(B)$, after 30 days of chemical disinfection (T1), and after 1008 hours of artificial aging (T2) for both Shore A hardness and color stability (Tables 2, 3). Tables 4, 5 and Figures 1, 2 show the mean and standard deviations for Shore A hardness and color stability for the experimental silicone after each testing period.

Table 4 shows that, in the GI group, neither the disinfecting solutions nor the artificial aging significantly reduced the hardness of the silicone material $(P>.05)$. In the GII group, the plant extract $\mathrm{HC}$ and the water with 
Table 4. Mean results (standard deviation) of Shore A hardness for each group, disinfecting solution, and period

\begin{tabular}{|c|c|c|c|c|}
\hline \multirow[b]{2}{*}{ Group } & \multirow[b]{2}{*}{ Disinfectant } & \multicolumn{3}{|c|}{ Period } \\
\hline & & Baseline & T1 & T2 \\
\hline \multirow[t]{5}{*}{ GI } & Saline solution & $33.3(1.39)^{\mathrm{Aa}}$ & $32.5(1.29)^{\mathrm{Aa}}$ & $35.3(1.49)^{\mathrm{Aa}}$ \\
\hline & Hidrastis canadensis & $33.8(1.22)^{\mathrm{Aa}}$ & $34.7(1.63)^{\mathrm{Aa}}$ & $35.5(1.23)^{\mathrm{Aa}}$ \\
\hline & Cymbopogon nardus & $33.4(1.19)^{\mathrm{Aa}}$ & $33.6(1.58)^{\mathrm{Aa}}$ & $33.9(1.72)^{\mathrm{Aa}}$ \\
\hline & Chlorhexidine $4 \%$ & $33.0(1.12)^{\mathrm{Aa}}$ & $33.1(1.95)^{\mathrm{Aa}}$ & $34.4(1.73)^{\mathrm{Aa}}$ \\
\hline & Neutral soap & $33.5(1.60)^{\mathrm{Aa}}$ & $33.1(1.88)^{\mathrm{Aa}}$ & $33.9(1.67)^{\mathrm{Aa}}$ \\
\hline \multirow[t]{5}{*}{ GII } & Saline solution & $34.6(1.30)^{\mathrm{Aa}}$ & $31.7(0.78)^{\mathrm{Aa}}$ & $34.7(1.27)^{\mathrm{Aa}}$ \\
\hline & Hidrastis canadensis & $35.4(1.49)^{\mathrm{Aa}}$ & $31.2(0.73)^{\mathrm{Ab}}$ & $34.4(1.27)^{\mathrm{Aab}}$ \\
\hline & Cymbopogon nardus & $34.5(1.14)^{\mathrm{Aa}}$ & $32.0(0.93)^{\mathrm{Aa}}$ & $33.3(2.20)^{\mathrm{Aa}}$ \\
\hline & Chlorhexidine $4 \%$ & $35.5(1.66)^{\mathrm{Aa}}$ & $32.5(0.52)^{\mathrm{Aa}}$ & $34.4(1.81)^{\mathrm{Aa}}$ \\
\hline & Neutral soap & $36.1(1.43)^{\mathrm{Aa}}$ & $31.7(1.10)^{\mathrm{Ab}}$ & $33.5(2.16)^{\mathrm{Aab}}$ \\
\hline \multirow[t]{5}{*}{ GIII } & Saline solution & $32.5(1.61)^{\mathrm{Aa}}$ & $30.8(2.38)^{\mathrm{ABa}}$ & $32.5(0.85)^{\mathrm{Aa}}$ \\
\hline & Hidrastis canadensis & $30.8(2.14)^{\mathrm{Aab}}$ & $27.9(2.23)^{\mathrm{Aa}}$ & $31.3(1.65)^{\mathrm{Ab}}$ \\
\hline & Cymbopogon nardus & $32.3(1.18)^{\mathrm{Aa}}$ & $32.3(1.72)^{\mathrm{Ba}}$ & $31.7(1.21)^{\mathrm{Aa}}$ \\
\hline & Chlorhexidine $4 \%$ & $32.4(2.00)^{\mathrm{Aa}}$ & $30.3(1.77)^{\mathrm{ABa}}$ & $33.4(2.14)^{\mathrm{Aa}}$ \\
\hline & Neutral soap & $31.7(2.05)^{\mathrm{Aa}}$ & $31.0(2.92)^{\mathrm{ABa}}$ & $33.3(1.39)^{\mathrm{Aa}}$ \\
\hline \multirow[t]{5}{*}{ GIV } & Saline solution & $34.9(1.91)^{\mathrm{Aa}}$ & $33.2(2.22)^{\mathrm{ABCa}}$ & $32.9(2.10)^{\mathrm{Aa}}$ \\
\hline & Hidrastis canadensis & $33.7(2.52)^{\mathrm{Aa}}$ & $31.3(3.22)^{\mathrm{BCa}}$ & $31.2(2.26)^{\mathrm{Aa}}$ \\
\hline & Cymbopogon nardus & $35.4(1.24)^{\mathrm{Aa}}$ & $34.2(1.84)^{\mathrm{ABa}}$ & $32.8(1.86)^{\mathrm{Aa}}$ \\
\hline & Chlorhexidine $4 \%$ & $33.5(1.30)^{\mathrm{Aa}}$ & $35.2(2.87)^{\mathrm{Aa}}$ & $32.4(1.23)^{\mathrm{Aa}}$ \\
\hline & Neutral soap & $34.4(2.02)^{\mathrm{Aa}}$ & $30.8(2.75)^{\mathrm{Cb}}$ & $32.3(1.64)^{\mathrm{Aab}}$ \\
\hline
\end{tabular}

Statistically significant differences between groups are indicated by different superscript uppercase letters (within column) and lowercase letters (within row).

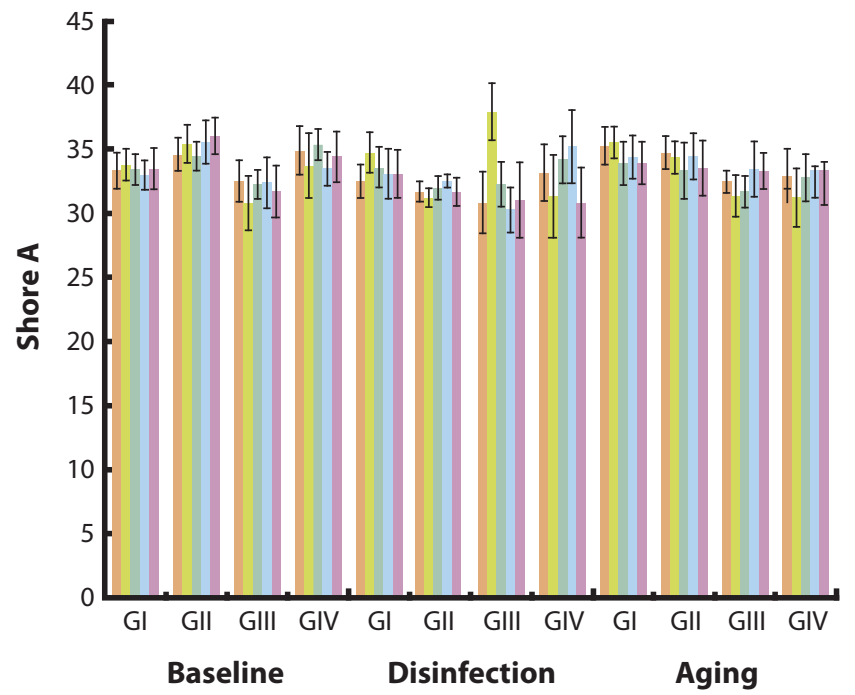

\begin{tabular}{|ll|}
\hline Saline Solution & Hydrastis canadensis \\
Cymbopogon nardus & Chlorhexidine $4 \%$ \\
Water and neutral soap & \\
\hline
\end{tabular}

Figure 1. Shore A results for all tested groups according to different disinfecting solutions and periods.

neutral soap significantly reduced the hardness in comparison with the baseline $(P<.05)$. The factor period was not significant in this group. In the GIII group, the plant extract $\mathrm{HC}$ showed more influence on the
Table 5. Mean results (standard deviation) of color stability $(\Delta \mathrm{E})$ for each group, disinfecting solution, and period

\begin{tabular}{|c|c|c|c|}
\hline \multirow[b]{2}{*}{ Group } & \multirow[b]{2}{*}{ Disinfectant } & \multicolumn{2}{|c|}{ Period } \\
\hline & & $T_{1} B$ & $T_{2} B$ \\
\hline \multirow[t]{5}{*}{$\mathrm{Gl}$} & Saline solution & $6.44(1.91)^{\mathrm{Aa}}$ & $2.18(1.07)^{\mathrm{Ab}}$ \\
\hline & Hidrastis canadensis & $7.68(1.53)^{\mathrm{Aa}}$ & $4.88(0.76)^{\mathrm{Ab}}$ \\
\hline & Cymbopogon nardus & $7.72(1.21)^{\mathrm{Aa}}$ & $2.63(1.40)^{\mathrm{Ab}}$ \\
\hline & Chlorhexidine 4\% & $7.65(1.35)^{\mathrm{Aa}}$ & $5.80(1.38)^{\mathrm{Aa}}$ \\
\hline & Neutral soap & $6.92(1.56)^{\mathrm{Aa}}$ & $3.90(1.79)^{\mathrm{Ab}}$ \\
\hline \multirow[t]{5}{*}{ GII } & Saline solution & $3.66(1.99)^{\mathrm{Aa}}$ & $5.55(2.93)^{\mathrm{Aa}}$ \\
\hline & Hidrastis canadensis & $3.37(1.80)^{\mathrm{Aa}}$ & $6.29(1.71)^{\mathrm{Aa}}$ \\
\hline & Cymbopogon nardus & $6.67(0.43)^{\mathrm{Aa}}$ & $6.63(3.29)^{\mathrm{Aa}}$ \\
\hline & Chlorhexidine $4 \%$ & $3.36(1.42)^{\mathrm{Aa}}$ & $6.34(3.26)^{\mathrm{Aa}}$ \\
\hline & Neutral soap & $3.67(1.33)^{\mathrm{Aa}}$ & $4.98(2.10)^{\mathrm{Aa}}$ \\
\hline \multirow[t]{5}{*}{ GIII } & Saline solution & $7.27(2.47)^{\mathrm{Aa}}$ & $4.72(1.85)^{\mathrm{Aa}}$ \\
\hline & Hidrastis canadensis & $12.52(1.86)^{\mathrm{Ba}}$ & $9.38(4.87)^{\mathrm{Ba}}$ \\
\hline & Cymbopogon nardus & $12.60(4.73)^{\mathrm{Ba}}$ & $6.06(2.93)^{\mathrm{ABb}}$ \\
\hline & Chlorhexidine $4 \%$ & $12.51(3.23)^{\mathrm{Ba}}$ & $9.10(3.29)^{\mathrm{Ba}}$ \\
\hline & Neutral soap & $8.27(1.11)^{\mathrm{Aa}}$ & $4.80(2.33)^{\mathrm{Aa}}$ \\
\hline \multirow[t]{5}{*}{ GIV } & Saline solution & $6.60(1.57)^{\mathrm{Aa}}$ & $3.09(2.38)^{\mathrm{Aa}}$ \\
\hline & Hidrastis canadensis & $8.45(3.77)^{\mathrm{Aa}}$ & $6.69(3.58)^{\mathrm{Aa}}$ \\
\hline & Cymbopogon nardus & $9.29(1.80)^{\mathrm{Aa}}$ & $4.76(2.07)^{\mathrm{Ab}}$ \\
\hline & Chlorhexidine $4 \%$ & $8.48(2.34)^{\mathrm{Aa}}$ & $6.39(1.94)^{\mathrm{Aa}}$ \\
\hline & Neutral soap & $6.27(1.80)^{\mathrm{Aa}}$ & $3.90(0.73)^{\mathrm{Aa}}$ \\
\hline
\end{tabular}

Statistically significant differences between groups are indicated by different superscript uppercase letters (within column) and lowercase letters (within row).
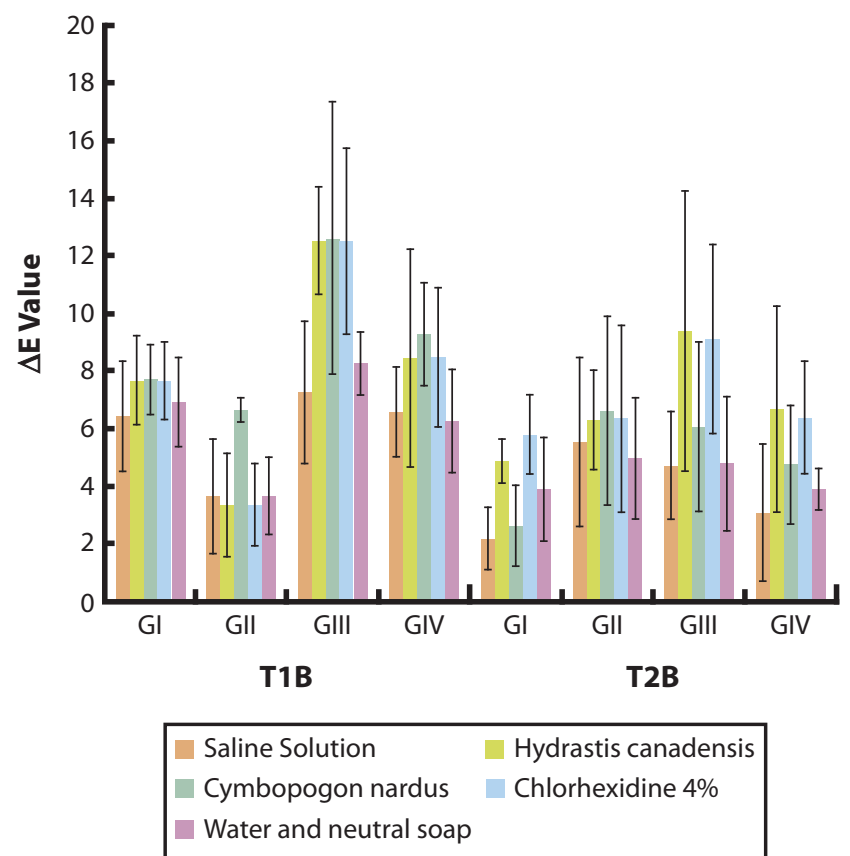

Figure 2. Color results $(\Delta \mathrm{E})$ for all tested groups according to different disinfecting solutions and different periods.

hardness reduction, which was significantly different from $\mathrm{CN}(P<.05)$. Artificial aging did not affect the hardness of the analyzed subgroups, except for the subgroup disinfected with HC. In the GIV group, just 
Table 6. Mean results (standard deviation) of Shore A hardness for each pigmentation, baseline, and after disinfection protocols, regardless of disinfecting solution

\begin{tabular}{lcc}
\hline Groups & Baseline & T1 \\
\hline GI & $33.4(1.30)^{\mathrm{Aa}}$ & $33.4(1.66)^{\mathrm{Aa}}$ \\
\hline GII & $35.2(1.40)^{\mathrm{Ba}}$ & $31.8(0.81)^{\mathrm{Bb}}$ \\
\hline GIII & $31.9(1.79)^{\mathrm{Ca}}$ & $30.5(2.20)^{\mathrm{Ca}}$ \\
\hline GIV & $34.4(1.79)^{\mathrm{Aba}}$ & $32.9(2.58)^{\mathrm{ABb}}$ \\
\hline
\end{tabular}

Statistically significant differences between groups are indicated by different superscript uppercase letters (within column) and lowercase letters (within row).

cleaning with water and neutral soap significantly reduced hardness. When the disinfecting solutions were compared, the HC had more influence on hardness reduction, which was statistically different from $\mathrm{CN}$ and CHX $(P<.05)$. Artificial aging did not have a significant influence on any of the tested subgroups $(P>.05)$. Table 6 shows the comparison among groups, which revealed that the opacifier significantly increased the hardness of the silicone (GII; $35.23 \pm 1.4$ ) in comparison with the baseline (GI), while the medium-shade pigment promoted its reduction (GIII; $31.93 \pm 1.79$ ) $(P<.05)$. However, the black pigment (GIV) showed hardness similar to the colorless group (GI) and the colorless with the opacifier group (GII) ( $P>.05$ ).

Regarding color stability, the specimens for all groups showed a numeric alteration in $\Delta \mathrm{E}$ values depending on the disinfection and the artificial aging: $\Delta \mathrm{E}>0$ (Table 5). In the pigmented groups (GIII and GIV), artificial aging significantly reduced the $\Delta \mathrm{E}$ values $(P<.05)$ for subgroups disinfected with $\mathrm{CN}$. The GII group showed the lowest color alteration after the disinfecting procedure $(P<.05)$. Artificial aging did not promote color alteration for the GII $(P>.05)$, regardless of the disinfecting solution. The GIII group showed the highest values of $\Delta \mathrm{E}(P>.05)$ in comparison with the other groups (Table 7), although they were statistically similar to those of the GII group after aging (T2). A significant difference was found between the $\Delta \mathrm{E}$ values of the specimens disinfected with $\mathrm{HC}, \mathrm{CN}$, and $\mathrm{CHX}$ and specimens subjected to saline solution and neutral soap (Table 8).

Because a significant difference was found in the hardness of the specimens pigmented with black and medium-shade pigments, representative EDS images have been inserted. Figure 3 shows the mapping of the surface of the colorless pigment, revealing that the bulk properties consisted mainly of silicon (Si) elements because the specimens were based on a polymer of dimethylsiloxane. The surface of the specimen with medium-shade pigment (GIII) (Fig. 4) shows its bulk properties consisted of $\mathrm{Si}$, oxygen $(\mathrm{O})$, and iron $(\mathrm{Fe})$. Figure 5 lists the bulk properties of the specimen with black pigment (GIV) consisted mainly of oxygen $(\mathrm{O})$, carbon $(\mathrm{C})$, cobalt $(\mathrm{Co})$, and silicon $(\mathrm{Si})$.
Table 7. Mean results (standard deviation) of color stability $(\Delta E)$ for each group and period, regardless of disinfecting solution

\begin{tabular}{lcc}
\hline & \multicolumn{2}{c}{ Period } \\
\cline { 2 - 3 } Group & $\mathbf{T}_{\mathbf{1}} \mathbf{B}$ & $\mathbf{T}_{\mathbf{2}} \mathbf{B}$ \\
\hline $\mathrm{GI}$ & $7.28(1.51)^{\mathrm{Aa}}$ & $3.88(1.28)^{\mathrm{Ab}}$ \\
\hline GII & $4.15(1.40)^{\mathrm{Ba}}$ & $5.96(2.66)^{\mathrm{BCa}}$ \\
\hline GIII & $10.63(2.68)^{\mathrm{Ca}}$ & $6.81(3.05)^{\mathrm{Cb}}$ \\
\hline GIV & $7.82(2.26)^{\mathrm{Aa}}$ & $4.97(2.14)^{\mathrm{ABb}}$ \\
\hline
\end{tabular}

Statistically significant differences between groups are indicated by different superscript uppercase letters (within column) and lowercase letters (within row).

Table 8. Mean results (standard deviation) of color stability $(\Delta E)$ for each period and disinfecting solution, regardless of group

\begin{tabular}{lcc}
\hline \multirow{2}{*}{ Group } & \multicolumn{2}{c}{ Period } \\
\cline { 2 - 3 } Saline solution & $\mathbf{T}_{\mathbf{1}} \mathbf{B}$ & $\mathbf{T}_{\mathbf{2}} \mathbf{B}$ \\
\hline Hidrastis canadensis & $5.99(1.98)^{\mathrm{Aa}}$ & $3.88(2.06)^{\mathrm{Ab}}$ \\
\hline Cymbopogon nardus $^{\mathrm{Ba}}$ & $8.00(2.24)^{\mathrm{Ba}}$ & $6.81(2.73)^{\mathrm{Ba}}$ \\
\hline Chlorhexidine 4\% $_{\text {Neutral soap }}^{\mathrm{Ab}}$ & $9.07(2.04)^{\mathrm{Ba}}$ & $5.02(2.42)^{\mathrm{Ab}}$ \\
\hline
\end{tabular}

Statistically significant differences between groups are indicated by different superscript uppercase letters (within column) and lowercase letters (within row).

\section{DISCUSSION}

The null hypothesis that the disinfection and artificial aging of the silicone elastomer MDX4-4210 would not affect its hardness and color stability was rejected because the silicone material's hardness and color were affected by artificial aging, the use of a dry opacifier and oil pigments, and disinfecting solutions.

Recently, the incorporation of oil pigments and dry opacifiers into the silicon matrix to lengthen the lifetime of maxillofacial silicone prostheses has been proposed, because this strategy improves their color stability and protects the silicone material from UVB rays, environmental factors, and aging. ${ }^{13,18,19}$ However, other studies have revealed that the incorporation of such ingredients may affect the properties of silicone elastomers. ${ }^{13,24,34}$ In the present study, the opacifier promoted the lowest color alteration in the experimental groups, regardless of the disinfecting solution. The opacifier inhibited the effects of artificial aging and promoted color stability, except in the subgroup disinfected with $\mathrm{CN}$, which showed a significant reduction in the $\Delta \mathrm{E}$ values. The subgroups disinfected with $\mathrm{CN}$ showed the highest $\Delta \mathrm{E}$ values before artificial aging. Possibly, this solution promoted an extrinsic pigmentation. However, after artificial aging, this subgroup showed a reduction in $\Delta \mathrm{E}$ values, in that the exposure to water, temperature, and UV lights removed this extrinsic pigmentation promoted by the disinfecting solution. The same result was found in the colorless group, in which all the subgroups showed reduced $\Delta \mathrm{E}$ values after artificial aging. Clearly, artificial aging tends to promote color alteration in colorless silicone, reducing 


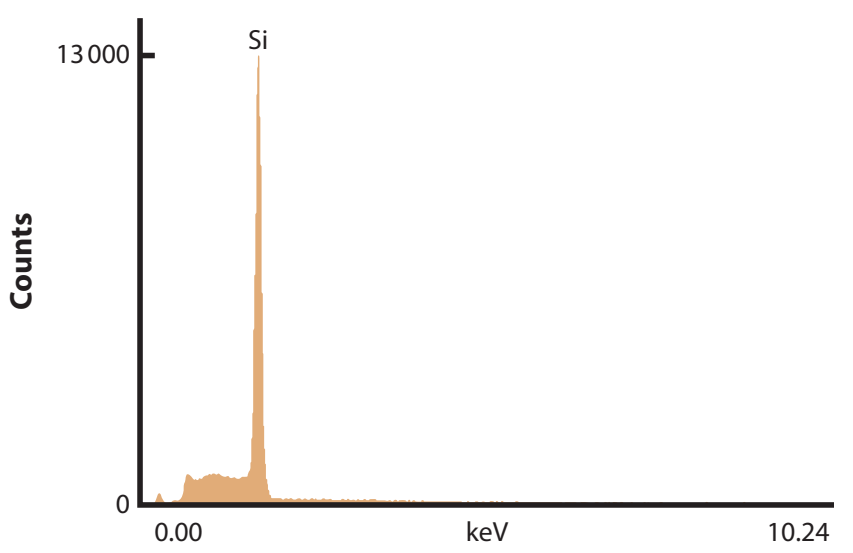

Figure 3. Representative energy dispersive spectroscopy image of colorless silicone material (MDX4-4210).

the $\Delta \mathrm{E}$ values and potentially discoloring the silicone material. However, the opacifier helped preserve color over time, which is in agreement with other studies. ${ }^{13,18,19}$

The GI group was the only group not affected by the tested factors. This may have occurred because of the structural chain of the silicone rubber [poly(dimethylsiloxane), $\mathrm{PDMS}^{\mathrm{X}}$ ], which is composed of $\mathrm{Si}-\mathrm{O}$ bonds surrounded by methyl groups $\left(-\mathrm{O}-\mathrm{Si}-\mathrm{CH}_{3}\right)$. This structure is different from that of natural rubber (hydrocarbons polymers, $-\mathrm{C}=\mathrm{C}-\mathrm{CH}_{3}$ ), which has unsaturations; this structure provides silicone elastomer with resistance to some environmental conditions. Thus, disinfection and artificial aging did not affect the tested silicone elastomer (GI). However, alterations clearly occurred in the opacifier and pigment groups, and the opacifier $(\mathrm{ZnO})$ significantly increased the hardness of the silicone material. ${ }^{10,13,14}$ The incorporation of these particles should be performed carefully because silicone elastomers should be flexible enough to follow facial movements. ${ }^{15,24}$ In addition, the type and concentration of pigment may influence the elastic and viscous portion of the properties of maxillofacial elastomeric materials; increasing the concentration of pigment decreases the energy absorption capacity. ${ }^{15}$

When groups were compared, the group with the medium-shade pigment (GIII) showed the lowest hardness at baseline but the highest color alteration $(\Delta \mathrm{E}=10.63 \pm 2.68)$. The addition of this pigment may have affected the polymerization process of the silicone material. The manufacturer confirmed that this method of intrinsic pigmentation is a mixture of crushed cosmetic pigments and silicone oil fluid that is compatible with all silicone materials. The medium-shade pigment likely acted as a plasticizer, minimizing the networking of the polymeric chains of the silicone. ${ }^{9}$ This hypothesis is corroborated by the manufacturer's instructions, which state that its resilience and physical properties may be affected if a silicone fluid is mixed with the silicone matrix.

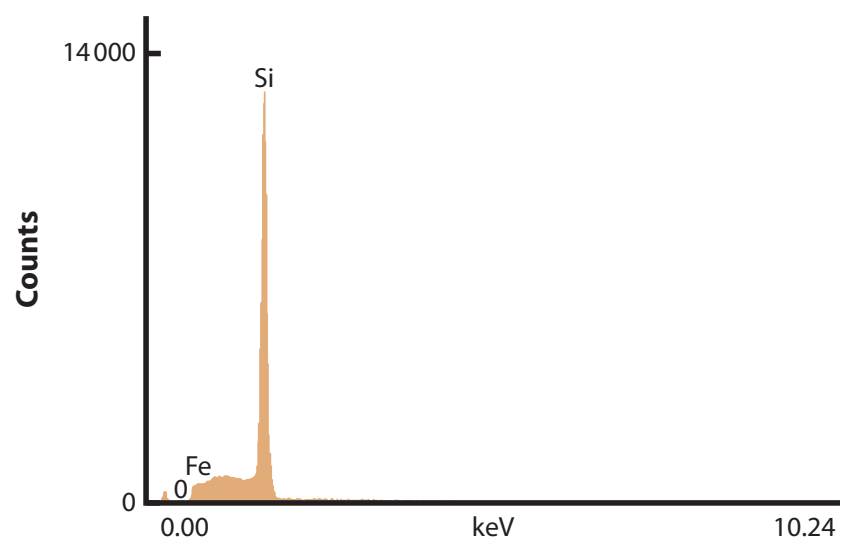

Figure 4. Representative energy dispersive spectroscopy image of pigmented silicone material (MDX4-4210) medium shade pigment.

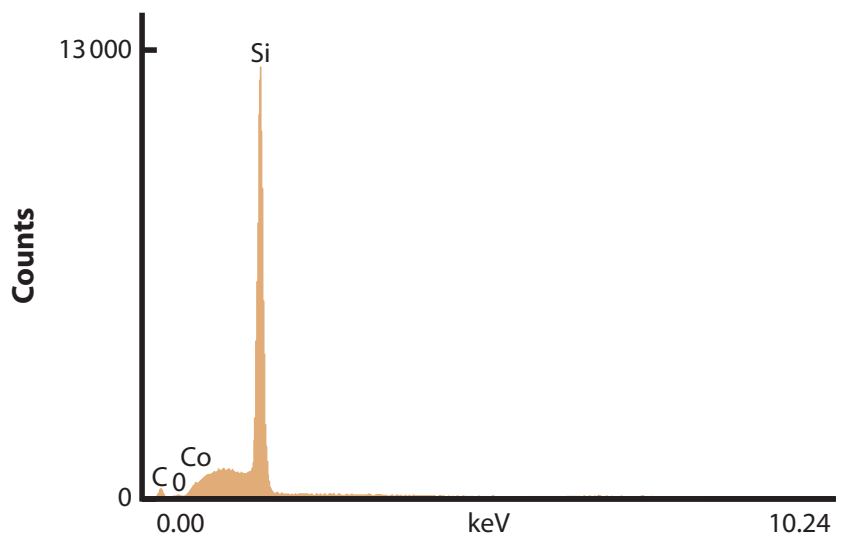

Figure 5. Representative energy dispersive spectroscopy image of pigmented silicone material (MDX4-4210) black shade pigment.

Thus, the highest mean $\Delta \mathrm{E}$ for the GIII group might be explained by the lower interaction of the medium-shade pigment with the silicone matrix. This may have caused the greater susceptibly of this group to the alterations promoted by the cleaning and disinfection procedures.

This behavior, however, was not observed in the GI group, which was statistically similar to the GI and GII groups for hardness and statistically similar to the GI group for color stability $(\Delta \mathrm{E})$. In this context, EDS analysis was performed, and, according to this test, Fe and $\mathrm{O}$ were present in the medium-shade pigment. The different behaviors of the specimens in the GIII and GIV groups may be explained by the difference in the pigment composition (Figs. 4, 5). The cobalt (Co) likely worked as a filler particle and did not reduce hardness in the GIV group.

After artificial aging, a nonsignificant alteration was noted in the hardness of all tested groups when compared with the baseline. This result is advantageous, in that many studies show that artificial aging increases the hardness of the material, probably as the result of the 
continuous polymerization that elastomer materials show over time. ${ }^{20,24}$ Other studies have explained these changes in properties by alterations in the chemical structure of the polymer chains induced by the hot and humid environment. The alterations are mainly photooxidation of the polymers, with free radical formation (polymer oxy- and peroxyradicals) that would lead to chain scission. Other free radicals might react with each other, leading to crosslinking. ${ }^{12}$ All those events occur simultaneously with the creation of microcracks, hardening, and the loss of color and brightness. ${ }^{18}$ However, because aging chambers reproduce more extreme environmental conditions than occur during a patient's daily routine, such phenomena are less evident in the clinical performance of silicone prostheses. ${ }^{24}$

The results of the present study suggest that chemical disinfecting solutions should be the first choice for cleaning maxillofacial silicone prostheses because continuous digital friction may promote the detachment of pigments on their surface. ${ }^{18,24}$ Cleaning the silicone material with water and neutral soap significantly reduced the hardness of the GII and GIV groups. In addition, other authors have reported that changes in elastomers after disinfection with the antimicrobial solutions used in this study are probably caused by the decomposition of the cleaning solutions into carbon monoxide, carbon dioxide, and sulfur dioxide, which could lead to either a hardening or a softening of materials. ${ }^{8,21-23}$ This may explain why HC extract significantly reduced the hardness of the GII, GIII, and GIV groups. This extract probably also affected the resistance to compression of the pigments and opacifiers, leading to the particles being more susceptible to fracture and dissolution and producing lower resistance to penetration loading for the groups with pigments and opacifiers. ${ }^{24}$ For color stability $(\Delta \mathrm{E})$, the disinfecting solutions ( $\mathrm{CHX}, \mathrm{HC}$, and $\mathrm{CN}$ ) showed similar behavior, regardless of the group, but higher $\Delta \mathrm{E}$ values in comparison with saline solution (SS) and water and neutral soap (WN).

In general, maxillofacial silicone prostheses are considered effective for 6 months to 1 year ${ }^{5}$ because of color instability, ${ }^{10,11}$ the deterioration of their margins and texture, and the increase in their hardness., ${ }^{4,5}$ Dentists and patients must minimize the factors that may affect the properties of silicone elastomers to improve their lifetime. Even though the MDX4-4210 hardness was affected as a result of aging, opacifier and pigments, and disinfecting solutions, the mean hardness results of all tested groups was considered acceptable for maxillofacial prostheses after 6 months to 1 year use (25 to 35 Shore A units). ${ }^{35}$ However, for color stability, almost all the experimental groups showed $\Delta \mathrm{E}$ values greater than 3.3 , making them clinically unacceptable, regardless of the use of disinfecting solutions. ${ }^{40-43}$ In summary, the statistically significant differences for hardness with regard to the experimental disinfecting solutions ( $\mathrm{HC}$ and $\mathrm{CN}$ ) did not seem to affect clinical performance in the silicone material over time, especially for silicone combined with compounds (pigments/opacifier).

The present study had some limitations. Only 1 silicone material was tested. In addition, the method used for artificial aging of the specimens was different from the mechanism to which maxillofacial silicone elastomers are naturally subjected. ${ }^{17}$ Moreover, the present study manually incorporated the pigments. Further studies are necessary to improve the incorporation of such pigments into the silicone matrix so that more homogenous mixtures are obtained and the chemical interaction of both materials is improved.

\section{CONCLUSIONS}

The hardness of MDX4-4210 after the experimental procedure was considered clinically acceptable for facial prostheses. All groups showed clinically unacceptable color alterations, regardless of the disinfecting solution.

\section{REFERENCES}

1. Karayazgan B, Gunay Y, Evlioglu G. Improved edge strength in a facial prosthesis by incorporation of tulle: a clinical report. J Prosthet Dent 2003; $90: 526-9$.

2. Bellamy KE, Waters MG. Designing a prosthesis to simulate the elastic properties of skin. Biomed Mater Eng 2005:15:21-7.

3. Guiotti AM, Goiato MC, Santos DM. Marginal deterioration of the silicone for facial prosthesis with pigments after effect of storage period and chemical disinfection. J Craniofac Surg 2010;21:142-5.

4. Mohite UH, Sandrik JL, Land MF, Byrne G. Environmental factors affecting mechanical properties of facial prosthetic elastomers. Int J Prosthodont 1994:7:479-86.

5. Lemon JC, Chambers MS, Jacobsen ML, Powers JM. Color stability of facial prostheses. J Prosthet Dent 1995;6:613-8.

6. Ishigami T, Tanaka Y, Kishimoto Y, Okada M. A facial prosthesis made of porcelain fused to metal: a clinical report. J Prosthet Dent 1997;77: 563-7.

7. Guiotti AM, Goiato MC, Santos DM. Evaluation of the Shore A hardness of silicone for facial prosthesis as to the effect of storage period and chemical disinfection. J Craniofac Surg 2010;21:323-7.

8. Hatamleh MM, Watts DC. Mechanical properties and bonding of maxillo facial silicone elastomers. Dent Mater 2010;26:185-91.

9. dos Santos DM, Goiato MC, Moreno A, Pesqueira AA, Dekon SFC, Guiotti AM. Effect of addition of pigments and opacifier on the hardness, absorption, solubility and surface degradation of facial silicone after artificial ageing. Polym Degrad Stab 2012;97:1249-53.

10. Haug SP, Andres CJ, Moore BK. Color stability and colorant effect on maxillofacial elastomers. Part I: colorant effect on physical properties. J Prosthet Dent 1999;81:418-22

11. Haug SP, Moore BK, Andres CJ. Color stability and colorant effect on maxillofacial elastomers. Part II: weathering effect on physical properties. J Prosthet Dent 1999:81:423-30.

12. Al-Harbi FA, Ayad NM, Saber MA, ArRejaie AS, Morgano SM. Mechanical behavior and color change of facial prosthetic elastomers after outdoor weathering in a hot and humid climate. J Prosthet Dent 2015:113:146-51.

13. Han Y, Kiat-amnuay S, Powers JM, Zhao Y. Effect of nano-oxide concentration on the mechanical properties of a maxillofacial silicone elastomer. J Prosthet Dent 2008;100:465-73.

14. Han Y, Zhao Y, Xie C, Powers JM, Kiat-amnuay S. Color stability of pigmented maxillofacial silicone elastomer: effects of nano-oxides as opacifiers. J Dent 2010;38(Suppl 2):e100-5.

15. Hu X, Pan X, Johnston WM. Effects of pigments on dynamic mechanical properties of a maxillofacial prosthetic elastomer. J Prosthet Dent 2014;112: 1298-303.

16. Kiat-Amnuay S, Lemon JC, Powers JM. Effect of opacifiers on color stability of pigmented maxillofacial silicone A-2186 subjected to artificial aging. J Prosthodont 2002;11:109-16. 
17. Kiat-Amnuay S, Mekayarajjananonth T, Powers JM, Chambers MS, Lemon JC. Interactions of pigments and opacifiers on color stability of MDX4-4210/type A maxillofacial elastomers subjected to artificial aging. J Prosthet Dent 2006;95:249-57.

18. Pesqueira AA, Goiato MC, dos Santos DM, Haddad MF, Ribeiro P, do P, Coelho Sinhoreti MA, et al. Effect of disinfection and accelerated aging on color stability of colorless and pigmented facial silicone. J Prosthodont 2011;20:305-9.

19. dos Santos DM, Goiato MC, Moreno A, Pesqueira AA, Haddad MF. Influence of pigments and opacifiers on color stability of an artificially aged facial silicone. J Prosthodont 2011;20:205-8.

20. Anusavice KJ, Shen C, Rawls HR. Phillips' science of dental materials. 12th ed. St. Louis: Elsevier, Saunders; 2013.

21. Eleni PN, Perivoliotis D, Dragatogiannis DA, Krokida MK, Polyzois GL, Charitidis CA, Ziomas I, Gettleman L. Tensile and microindentation properties of maxillofacial elastomers after different disinfecting procedures. J Mech Behav Biomed Mater 2013;28:147-55.

22. Eleni PN, Krokida MK, Polyzois GL, Gettleman L. Effect of different disinfecting procedures on the hardness and color stability of two maxillofacial elastomers over time. J Appl Oral Sci 2013;21:278-83.

23. Eleni PN, Krokida MK, Polyzois GL, Gettleman L. Dynamic mechanica thermal analysis of maxillofacial prosthetic elastomers: the effect of different disinfecting aging procedures. J Craniofac Surg 2014; 25:e251-5.

24. Goiato MC, Pesqueira AA, dos Santos DM, Zavanelli AC, Ribeiro P. Color Stability comparison of silicone facial prostheses following disinfection. J Prosthodont 2009;18:242-4.

25. Siriporn P, Mayura S. The effects of herbal essential oils on the ovipositiondeterrent and ovicidal activities of Aedes aegypti (Linn.), Anopheles dirus (Peyton and Harrison) and Culex quinquefasciatus (Say). Trop Biomed 2012;29:138-50.

26. Douglas LJ. Candida biofilms and their role in infection. Trends Microbiol 2003;11:30-6.

27. Nakahara K, Alzoreky NS, Yoshihashi T, Nguyen HTT, Trakoontivakorn G. Chemical composition and antifungal activity of essential oil from cymbopogon nardus. JARQ 2003;37:249-52.

28. Prasad CS, Shukla R, Kumar A, Dubey NK. In vitro and in vivo antifungal activity of essential oils of Cymbopogon martini and Chenopodium ambrosioides and their synergism against dermatophytes. Mycoses 2010;53:123-9

29. Moore DJ, Glaser ZR, Tabacco MJ, Linebaugh MG. Evaluation of polymeric materials for maxillofacial prosthetics. J Prosthet Dent 1977:38:319-26.

30. Yu R, Koran A 3rd, Craig RG. Physical properties of a pigmented silicone maxillofacial material as a function of accelerated aging. J Dent Res 1980;59: 1141-8.

31. Hatamleh MM, Watts DC. Effects of accelerated artificial daylight aging on bending strength and bonding of glass fibers in fiber-embedded maxillofacia silicone prostheses. J Prosthodont 2010;19:357-63.

32. ASTM International. ASTM D2240-05:2010 Standard test method for rubber property - durometer hardness. West Conshohocken: ASTM
International; 2010. Available at: http://www.astm.org/Standards/D2240. htm. Last accessed November 11, 2015.

33. Kazanji MN, Watkinson AC. Soft lining materials: their absorption of, and solubility in, artificial saliva. Br Dent J 1988;165:91-4.

34. Nouyen CT, Chambers MS, Powers JM, Kiat-Amnuay S. Effect of opacifiers and UV absorbers on pigmented maxillofacial silicone elastomer Part 2: Mechanical properties after artificial aging. J Prosthet Dent 2013;109:402-10

35. Lewis DH, Castleberry DJ. An assessment of recent advances in external maxillofacial materials. J Prosthet Dent 1980;43:426-32.

36. dos Santos DM, Goiato MC, Sinhoreti MA, Moreno A, Dekon SF, Haddad MF, Pesqueira AA. Influence of natural weathering on colour stability of materials used for facial prosthesis. J Med EngTechnol 2012;36:267-70

37. Haddad MF, Goiato MC, dos Santos DM, Moreno A, D'almeida NF, Pesqueira AA. Color stability of maxillofacial silicone with nanoparticle pigment and opacifier submitted to disinfection and artificial aging. J Biomed Opt 2011;16:095004.

38. Mancuso DN, Goiato MC, Santos DM. Color stability after accelerated aging of two silicones, pigmented or not, for use in facial prostheses. Braz Oral Res 2009;23:144-8.

39. Commission Internationale de l'Eclairage (CIE). Colorimetry-official recommendations of the Commission Internationale de l'Eclairage. CIE Publication No. 15 (E-1.3.1). Vienna (Austria): Bureau Central de la CIE, 1996.

40. Miyagawa Y, Powers JM, O’Brien WJ. Optical properties of direct restorative materials. J Dent Res 1981;60:890-4.

41. Um CM, Ruyters IE. Staining of resin-based veneering materials with coffee and tea. Quintessence Int 1991;22:377-86.

42. Brook AH, Smith RN, Lath DI. The clinical measurement of tooth color and stain. Int Dent J 2007;57:324-30.

43. Sarkis E. Color change of some aesthetic dental materials: Effect of immersion solutions and finishing of their surfaces. Saudi Dent J Apr 2012;24:85-9.

44. ASTM G53-96. Standard Practice for operating light- and water-exposure apparatus (fluorescent UV-condensation type) for exposure of nonmetallic materials (Withdrawn 2000). Philadelphia: ASTM, 1996.

45. Della Bona A, Corazza PH, Zhang Y. Characterization of a polymer-infiltrated ceramic-network material. Dent Mater 2014;30:564-9.

\section{Corresponding author:}

Dr Aimée Maria Guiotti

Department of Dental Materials and Prosthodontics

São Paulo State University (UNESP)

José Bonifácio, 1153

Araçatuba, São Paulo

BRAZIL

Email: aimee@foa.unesp.br

Copyright (C) 2016 by the Editorial Council for The Journal of Prosthetic Dentistry. 